Int. J. Electrochem. Sci., 16 (2021) Article ID: 210731

International Journal of

ELECTROCHEMICAL

SCIENCE

www.electrochemsci.org

\title{
Pydridoxal (thio) Semicarbazone Ligands and Their Fe(III) Complexes as Potential Electrocatalysts for Hydrogen Evolution Raction
}

\author{
Violeta Jevtovic $^{1, *}$, Khalaf M. Alenezi ${ }^{1}$, Hani El Moll ${ }^{1}$, Ashanul Haque ${ }^{1}$, Jamal Humaidi ${ }^{1}$, \\ Salma A. Al-Zahrani ${ }^{1}$, Dragoslav Vidovic ${ }^{2}$ \\ ${ }^{1}$ Chemistry Department, University Hail, Kingdom of Saudi Arabia, \\ ${ }^{2}$ School of Chemistry, Monash University, Clayton, Melbourne, Australia. \\ *E-mail : v.jevtovic@uoh.edu.sa
}

doi: $10.20964 / 2021.07 .61$

Received: 16 March 2021 / Accepted: 27 April 2021 / Published: 31 May 2021

A significant requirement for a future hydrogen economy and easily accessible renewable energy is efficient production of hydrogen from aqueous protons by direct solar energy conversion. The synthesis of a catalyst that can facilitate the reaction of hydrogen evolution (HER) is of paramount importance to achieve this overall objective. This study focuses on catalytical activity of pyridoxal-semi $\left(\mathrm{H}_{2}-\mathrm{PLSC}\right)$ and pyridoxal-thiosemi ( $\mathrm{H}_{2}$-PLTSC) carbazone molecules and their iron complexes $\mathrm{Fe}(\mathrm{H}$ PLTSC)(PLTSC)] $4 \mathrm{H}_{2} \mathrm{O}$ and $\left[\mathrm{Fe}\left(\mathrm{H}_{2}-\mathrm{PLSC}\right) \mathrm{Cl}_{2}\left(\mathrm{H}_{2} \mathrm{O}\right)\right] \mathrm{Cl}$, for electrochemical proton reduction into hydrogen. The free ligands ( $\mathrm{H}_{2}-\mathrm{PLSC}$ and $\mathrm{H}_{2}$-PLTSC) were able to electrocatalyze the reduction of proton into hydrogen. Even though, the studied complexes were more catalytically active than the free ligand, this observation provided crucial evidence for the proposed mechanism that involved protonation of the ligand.

Keywords: Pyridoxal-semicarbazone, Pyridoxal-tiosemicarbazone, Iron complexes, electrocatalysis

\section{$\underline{\text { FULL TEXT }}$}

(C) 2021 The Authors. Published by ESG (www.electrochemsci.org). This article is an open access article distributed under the terms and conditions of the Creative Commons Attribution license (http://creativecommons.org/licenses/by/4.0/). 